\title{
(2) OPEN ACCESS \\ Recent advances in clinical practice: colorectal cancer chemoprevention in the average-risk population
}

\author{
Nicolas Chapelle (D) ,' Myriam Martel, ${ }^{2}$ Esther Toes-Zoutendijk, ${ }^{3}$ Alan N Barkun (D) , \\ Marc Bardou (D) ${ }^{4}$
}

- Additional material is published online only. To view please visit the journal online (http://dx.doi.org/10.1136/ gutjnl-2020-320990).

'Institut des Maladies de I'appareil digestif, Department of Gastroenterology, Hepatology, Nutrition and Medical Oncology, Service de Gastroenterologie, Nantes, France

2Department of Gastroenterology, McGil University Health Centre, Montreal, Quebec, Canada ${ }^{3}$ Public Health, Erasmus MC Rotterdam, The Netherlands ${ }^{4}$ CIC INSERM 1432, CHU Dijon Dijon, France

Correspondence to Professor Marc Bardou, CIC INSERM 1432, CHU Dijon, Dijon 21033, France;

marc.bardou@u-bourgogne.fr

Received 26 February 2020 Revised 15 April 2020 Accepted 21 May 2020 Published Online First 28 September 2020

\section{Check for updates}

(c) Author(s) (or their employer(s)) 2020. Re-use permitted under CC BY-NC. No commercial re-use. See rights and permissions. Published by BMJ.

To cite: Chapelle $\mathrm{N}$,

Martel M, Toes-Zoutendijk E, et al. Gut

2020;69:2244-2255.

\begin{abstract}
Colorectal cancer (CRC) is one of the most common and lethal malignancies in Western countries. Its development is a multistep process that spans more than 15 years, thereby providing an opportunity for prevention and early detection. The high incidence and mortality rates emphasise the need for prevention and screening. Many countries have therefore introduced CRC screening programmes. It is expected, and preliminary evidence in some countries suggests, that this screening effort will decrease CRCrelated mortality rates. CRC prevention involves a healthy lifestyle and chemoprevention-more specifically, oral chemoprevention that can interfere with progression from a normal colonic mucosa to adenocarcinoma. This preventive effect is important for individuals with a genetic predisposition, but also in the general population. The ideal chemopreventive agent, or combination of agents, remains unknown, especially when considering safety during longterm use. This review evaluates the evidence across 80 meta-analyses of interventional and observational studies of CRC prevention using medications, vitamins, supplements and dietary factors. This review suggests that the following factors are associated with a decreased incidence of CRC: aspirin, non-steroidal anti-inflammatory drugs, magnesium, folate, a high consumption of fruits and vegetables, fibre and dairy products. An increased incidence of CRC was observed with frequent alcohol or meat consumption. No evidence of a protective effect for tea, coffee, garlic, fish and soy products was found. The level of evidence is moderate for aspirin, $\beta$-carotene and selenium, but is low or very low for all other exposures or interventions.
\end{abstract}

\section{INTRODUCTION}

Colorectal cancer (CRC) remains the third most commonly diagnosed cancer among both men and women in the US, ${ }^{1}$ with a cumulative lifetime risk of developing CRC of $5 \%$ in the general population. ${ }^{2}$ In the USA, it is the second leading cause of cancer-related deaths in men and the third in women. ${ }^{1}$ Its global burden is expected to increase by $60 \%$ to more than 2.2 million new cases and 1.1 million cancer deaths by $2030 .{ }^{3}$ Whereas CRC mortality has been declining in most developed countries, diverging trends have been observed for incidence rates, with some countries having noted a decrease, such as in the USA, France or Japan, while others have reported an increase, such as in Canada, the UK or the Netherlands. ${ }^{3}$ As CRC has a natural history that spans over more than 15 years, from normal mucosa to overt cancer, it provides a window of opportunity for effective prevention. ${ }^{4}$
Randomised clinical trials (RCTs) have shown that biennial screening with faecal occult blood testing reduces mortality by $15 \%$ through the detection and subsequent removal of advanced adenomas or by diagnosing CRC at an early stage. ${ }^{5}$ Nevertheless, there is a wide heterogeneity in screening uptake across countries (ranging from $21 \%$ to $73 \%){ }^{6}$ and indeed across different population groups, including heterogeneity according to socioeconomic factors. ${ }^{7}$ In addition to increasing screening uptake, promotion of a healthy lifestyle is of great importance.

The following work is an umbrella review of systematic reviews and meta-analyses of interventions targeting chemopreventive products for CRC, specifically in an average-risk population.

\section{METHODS}

\section{Search strategy}

We performed a systematic review searching Embase, Medline and ISI Web of Knowledge using a highly sensitive search strategy to identify meta-analyses or systematic reviews. The following combination of controlled vocabulary and text words, related to (1) colon or colorectal cancer (neoplasia, carcinoma, tumour, metastasis, malignancy) and (2) chemoprevention agents, were used, including medications (aspirin, non-steroidal anti-inflammatory drugs (NSAIDs), statin), vitamins or supplements (magnesium, calcium, folic acid, vitamin A, B, C, E, D, $\beta$-carotene and selenium), as well as dietary factors (coffee, tea, fish, dairy products, fibre, fruits and vegetables, meat and alcohol). All citations were independently reviewed by two authors ( $\mathrm{MB}$ and $\mathrm{MM}$ ) and any discrepancies were resolved through discussion. Recursive searches and cross-references were carried out using a 'similar articles' function and hand searches of identified articles.

\section{Study selection and patient population}

We identified all meta-analyses assessing the risk of colon, rectal or colorectal cancer and chemoprevention agents in an average-risk population. Any studies on specific high-risk populations, such as those with previous adenoma removal, diabetes mellitus, chronic inflammatory bowel disease or a genetic background that increases CRC risk, were excluded. We included all studies published in French or English between September 1980 and June 2019, and more specifically all meta-analyses that performed a complete systematic search of the literature coupled with a pooled analysis, with reported odds ratios (ORs), relative risks (RRs) or hazard ratios (HRs) and corresponding 95\% 
confidence intervals (95\% CIs). Meta-analyses that reported adjusted risk ratios (aRRs), or summary relative risk estimates (SRREs) were also included.

Data were extracted by two independent reviewers (NC and MM) with the following information: authors, year of publication, search string, databases searches and dates of search, study inclusion and exclusion criteria, outcomes, number and design of included studies, number of patients, measure and category of exposure or intervention, type of cancer, study quality, heterogeneity, publication bias, effect size and 95\% CI. Specific data for men and women, colon subsites and dose and/or duration of intake for each studied component were also extracted, when available.

\section{Data analysis and quality assessment}

Owing to the heterogeneity of the collected information and comparisons, the overall effect on the incidence of CRC was analysed qualitatively and categorised as protective or no effect. Chemoprotective agents were qualified as 'protective effect' if the included meta-analysis showed an overall significant effect for the primary outcome and 'no effect' if no statistical difference was noted. We used the GRADE (Grading of Recommendations, Assessment, Development and Evaluations) rating of evidence to characterise the evidence of the effect of each studied factor on colorectal cancer incidence. ${ }^{8}$ Information on quality scores, publication bias and heterogeneity was included. Heterogeneity reported in the included meta-analyses was considered as low, moderate or severe for $\mathrm{I}^{2}<25 \%, 25-75 \%$ and $>75 \%$, respectively. When an $\mathrm{I}^{2}$ value was not provided, heterogeneity was defined as significant or not, based on a value below or above 0.05 , respectively. The quality of each meta-analysis is reported using the PRISMA (Preferred Reporting Items for Systematic Reviews and Meta-Analyses) checklist for metaanalyses and the AMSTAR (assessment of multiple systematic reviews) checklist for systematic reviews (data available on request).

\section{Patients and public involvement}

This paper is a systematic review for which we did not identify a specific need for patient involvement.

\section{Research ethics approval: human participants}

This paper is a systematic review of already published articles. Ethics approval was considered unnecessary as ethics approval had been considered by the original publications.

\section{RESULTS}

From the 2063 records initially identified, 343 full text articles were assessed for eligibility; 80 articles were finally included in the qualitative analysis of this umbrella review (figure 1). Summary of results, with the GRADING of evidence, is presented separately for medications, vitamins or nutrient supplements intake, any combination of vitamins and nutrient supplements, and for dietary factors (table 1). They have been classified according to

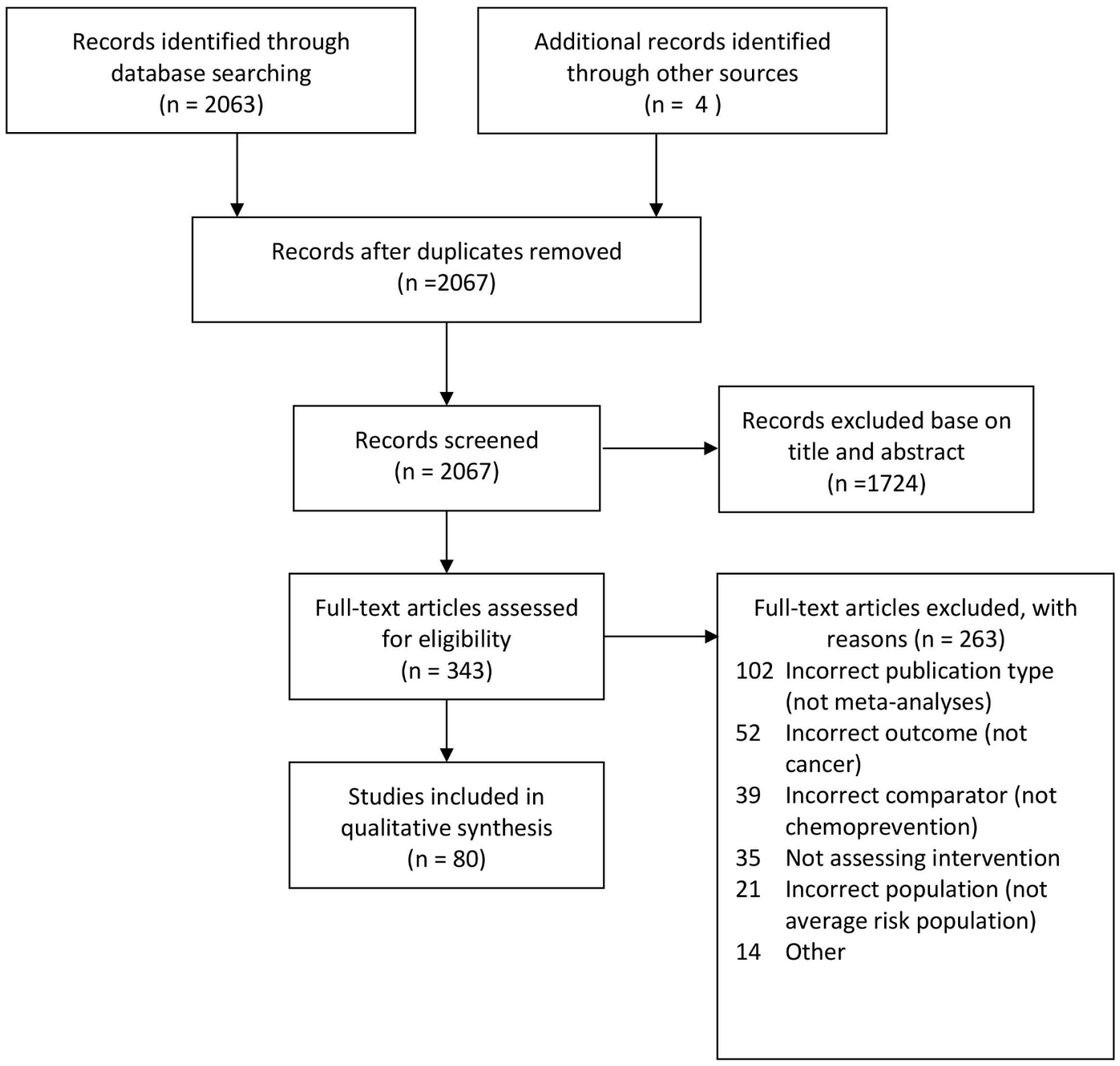

Figure 1 Quorum diagram. From: Moher D et al. ${ }^{97}$ 
Recent advances in clinical practice

Table 1 Summary of results of each component

\begin{tabular}{|c|c|c|c|c|}
\hline Component & $\begin{array}{l}\text { Number and type of meta-analyses } \\
\text { (reference) }\end{array}$ & Grade of overall certainty of evidence & $\begin{array}{l}\text { Overall effect on colorectal } \\
\text { cancer incidence }\end{array}$ & $\begin{array}{l}\text { Range of the effect* } \\
\text { (if significant) }\end{array}$ \\
\hline \multicolumn{5}{|c|}{ Components with protective effect on CRC risk } \\
\hline Aspirin & 4 Observational, ${ }^{9-12} 1 \mathrm{RCT}_{,}^{14} 1$ mixed $^{13}$ & $\begin{array}{l}\oplus \oplus \oplus \bigcirc \\
\text { Moderate } \\
\text { (serious inconsistency and suspected publication bias) }\end{array}$ & Protective & $-14 \%$ to $-29 \%$ \\
\hline Low-dose aspirin & 2 Observational, ${ }^{1012} 1 \mathrm{RCT}^{13}$ & $\begin{array}{l}\oplus \oplus \bigcirc \bigcirc \\
\text { Low } \\
\text { (serious inconsistency and suspected publication bias) }\end{array}$ & $\begin{array}{l}\text { Protective (observational) } \\
\text { No effect in RCT }\end{array}$ & \\
\hline NSAIDs & $\begin{array}{l}3 \text { Observational } \\
101516\end{array}$ & $\begin{array}{l}\oplus \oplus \bigcirc \bigcirc \\
\text { Low } \\
\text { (serious inconsistency and suspected publication bias) }\end{array}$ & Protective & $-27 \%$ to $-43 \%$ \\
\hline Magnesium & 3 Observational17-19 & $\begin{array}{l}\oplus \oplus \bigcirc \bigcirc \\
\text { Low }\end{array}$ & Protective & $-11 \%$ to $-22 \%$ \\
\hline Folic acid & 3 Observational ${ }^{20-22}$ & $\begin{array}{l}\oplus \bigcirc \bigcirc \bigcirc \\
\text { Very low } \\
\text { (serious inconsistency and indirectness, strong } \\
\text { suspected publication bias) }\end{array}$ & Protective & $-12 \%$ to $-15 \%$ \\
\hline Folic acid combination & $2 \mathrm{RCT}_{1}^{2324} 1$ mixed $^{25}$ & $\begin{array}{l}\oplus \bigcirc 0 \bigcirc \\
\text { Very low } \\
\text { (very serious indirectness) }\end{array}$ & No effect & NA \\
\hline Dairy products & 3 Observational ${ }^{26-28}$ & $\begin{array}{l}\oplus \bigcirc \bigcirc \bigcirc \\
\text { Very low } \\
\text { (serious inconsistency and very serious indirectness) }\end{array}$ & Protective/no effect & $-13 \%$ to $-19 \%$ \\
\hline Fibre & 5 Observational ${ }^{2629-32}$ & $\begin{array}{l}\oplus \bigcirc \bigcirc \bigcirc \\
\text { Very low } \\
\text { (serious inconsistency and very serious indirectness) }\end{array}$ & Protective effect (4) no effect (1) & $-22 \%$ to $-43 \%$ \\
\hline Fruits and vegetables & 9 Observational ${ }^{263033-39}$ & $\begin{array}{l}\oplus \bigcirc \bigcirc \bigcirc \\
\text { Very low } \\
\text { (serious inconsistency and very serious indirectness) }\end{array}$ & Protective effect (5) no effect (4) & $-8 \%$ to $-52 \%$ \\
\hline Soy & 3 Observational ${ }^{38-40}$ & $\begin{array}{l}\oplus \bigcirc \bigcirc \bigcirc \\
\text { Very low } \\
\text { (serious inconsistency and very serious indirectness) }\end{array}$ & Protective (2)/no effect (1) & $-8 \%$ to $-15 \%$ \\
\hline \multicolumn{5}{|c|}{ Components with no effect on CRC risk } \\
\hline Vitamin $\mathrm{E}$ & $5 \mathrm{RCT}_{1}{ }^{41-45} 2$ observational ${ }^{21} 22$ & $\begin{array}{l}\oplus \oplus \bigcirc \bigcirc \\
\text { Low } \\
\text { (serious indirectness) }\end{array}$ & No effect (6)/protective (1 Obs) & $-12 \%$ \\
\hline Vitamin C & 2 Observational, ${ }^{21} 221 \mathrm{RCT}^{44}$ & $\begin{array}{l}\oplus \bigcirc \bigcirc \bigcirc \\
\text { Very low } \\
\text { (serious inconsistency and very serious indirectness) }\end{array}$ & No effect & NA \\
\hline $\begin{array}{l}\text { Antioxidant } \\
\text { combinations }\end{array}$ & $4 \mathrm{RCT}_{,}^{41424445} 1$ observational ${ }^{21}$ & $\begin{array}{l}\oplus \bigcirc \bigcirc \bigcirc \\
\text { Very low } \\
\text { (very serious indirectness) }\end{array}$ & $\begin{array}{l}\text { No effect (4)/protective (one obs, } \\
\text { vitamin C combination) }\end{array}$ & $-17 \%$ \\
\hline$\beta$-Carotene & $3 \mathrm{RCT}^{42} 4546$ & $\begin{array}{l}\oplus \oplus \oplus \bigcirc \text { Moderate } \\
\text { (serious inconsistency) }\end{array}$ & No effect & NA \\
\hline $\begin{array}{l}\beta \text {-Carotene } \\
\text { combinations }\end{array}$ & $5 \mathrm{RCT}^{42} 44-47$ & $\begin{array}{l}\oplus \bigcirc \bigcirc \bigcirc \\
\text { Very low } \\
\text { (very serious indirectness) }\end{array}$ & No effect & NA \\
\hline Selenium & $3 \mathrm{RCT}^{42} 4445$ & $\oplus \oplus \oplus \bigcirc$ Moderate & No effect & NA \\
\hline Tea & 5 Observational ${ }^{2648-51}$ & $\begin{array}{l}\oplus \bigcirc 00 \\
\text { Very low } \\
\text { (serious inconsistency and very serious indirectness) }\end{array}$ & No effect (4)/protective effect (1) & $-18 \%$ \\
\hline Garlic and allium & 4 Observational $\left.\right|^{2152-54}$ & $\begin{array}{l}\oplus \bigcirc \bigcirc \bigcirc \\
\text { Very low } \\
\text { (serious inconsistency and very serious indirectness) }\end{array}$ & No effect/protective (1) & $-24 \%$ \\
\hline Vitamin D & 3 Observational, ${ }^{212256} 1 \mathrm{RCT}^{55}$ & $\begin{array}{l}\oplus \bigcirc \bigcirc \bigcirc \\
\text { Very low } \\
\text { (serious inconsistency and very serious indirectness) }\end{array}$ & No effect/Protective (2 Obs) & $-12 \%$ to $-13 \%$ \\
\hline Vitamin D+calcium & $2 \mathrm{RCT}^{55} 57$ & $\begin{array}{l}\oplus \bigcirc \bigcirc \bigcirc \\
\text { Very low } \\
\text { (very serious indirectness) }\end{array}$ & No effect & NA \\
\hline \multicolumn{5}{|c|}{ Components with unclear effect on CRC risk } \\
\hline Coffee & 7 Observational| $\left.\right|^{265-63}$ & $\begin{array}{l}\oplus \bigcirc \bigcirc \bigcirc \\
\text { Very low } \\
\text { (serious inconsistency and very serious indirectness) }\end{array}$ & No effect (4)/protective effect (3) & $-17 \%$ to $-24 \%$ \\
\hline Fish and omega-3 & 7 Observational ${ }^{263364-68}$ & $\begin{array}{l}\oplus \bigcirc \bigcirc \bigcirc \\
\text { Very low } \\
\text { (serious inconsistency and very serious indirectness) }\end{array}$ & No effect (4)/Protective (3) & $-7 \%$ to $-13 \%$ \\
\hline
\end{tabular}




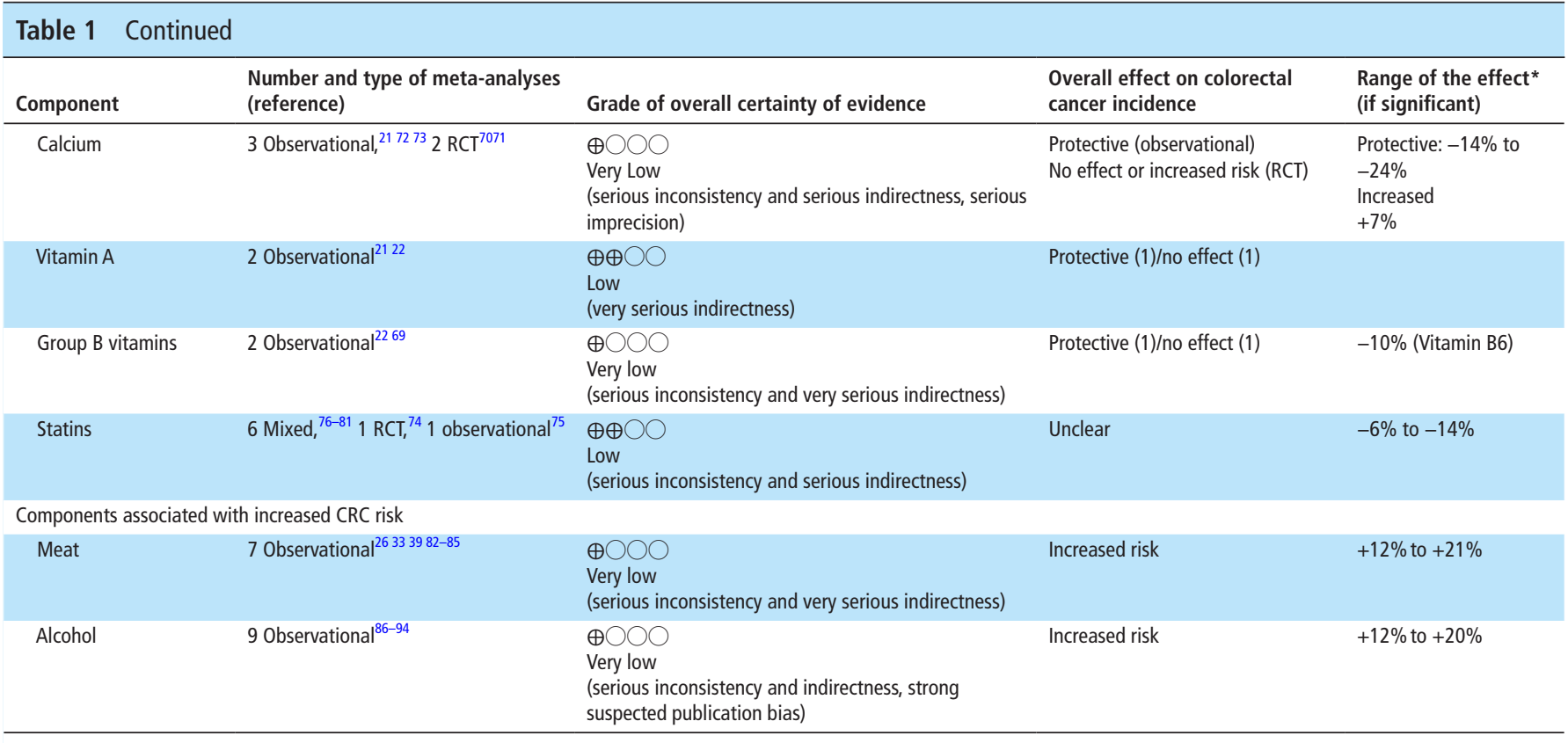

CRC, colorectal cancer; NA, Not applicable; NSAID, non-steroidal anti-inflammatory drug; RCT, randomised clinical trial.

their effect on CRC prevention as (i) protective, (ii) no effect, (iii) unclear effect or (iv) increasing risk of CRC. The characteristics and quality of included studies and the effect of each factor on CRC incidence are shown in table 2. Large variations were observed in quality, publication bias and between-study heterogeneity (table 2).

\section{Exposures or interventions associated with a protective effect on CRC prevention (supplementary table 1)}

Aspirin

Six meta-analyses, published between 2006 and 2017, evaluated the effect of aspirin. Four pooled results of observational studies only, ${ }^{9-12}$ one assessed both RCTs and observational studies, ${ }^{13}$ and the last RCTs only. ${ }^{14}$ Aspirin dose, frequency and treatment duration were reported separately in the meta-analysis by Ye et al, ${ }^{12}$ while the effect of low-dose aspirin (daily intake $\leq 325 \mathrm{mg} /$ day) on CRC prevention was evaluated in three meta-analyses. ${ }^{10} 1213$

A statistically significant protective effect of aspirin intake overall (RRs ranging from 0.71 to 0.86 ) was reported in the meta-analyses of both observational studies, ${ }^{9}{ }^{11-13}$ and RCTs. ${ }^{14}$ The magnitude of the protective effect was similar for colon cancer $(R R=0.71$ to 0.76$)$ and rectal cancer $(R R=0.68$ to 0.74$)$ when analysed separately. ${ }^{112}$ The protective effect in the colon may be limited to proximal colon cancers $(\mathrm{RR}=0.58 ; 95 \% \mathrm{CI}$ 0.46 to 0.74 ) as results for distal colon cancer did not reach statistical significance $(\mathrm{RR}=0.77,95 \% \mathrm{CI} 0.58$ to 1.04$) .{ }^{14}$ Increases in dosing, frequency and duration of intake were all independently associated with a decreased risk (RR ranging from 0.80 to 0.84 ), but were based on only one meta-analysis. ${ }^{12}$ Metaanalyses of low-dose aspirin (up to $325 \mathrm{mg} /$ day) found conflicting results, with either no protective effect, ${ }^{13}$ or a protective effect for a daily intake of aspirin as low as $75 \mathrm{mg} /$ day, ${ }^{10}$ with a possible dose-response effect and with RR ranging from 0.90 to 0.80 for daily intakes ranging from $75 \mathrm{mg}$ to $325 \mathrm{mg}$, respectively. ${ }^{12}$ Heterogeneity within the meta-analysis was noted in two of the studies included (with one quantified as strong). ${ }^{9} 11$

Despite serious inconsistencies across the meta-analyses and possible publication bias, the level of overall certainty was graded as moderate since the meta-analyses that included RCTs reported the strongest effects.

Summary: Based on RCT and observational studies, aspirin is protective in most of the included meta-analyses, the relative risks range from 0.71 to 0.86 . The protective effect may be observed even for doses as low as $75 \mathrm{mg} /$ day, with a doseresponse effect reported up to $325 \mathrm{mg} /$ day. Certainty of evidence is moderate.

Non-steroidal anti-inflammatory drugs (NSAIDs)

Three meta-analyses of observational studies published between 2007 and 2018 were included. ${ }^{10} 1516$ Overall, NSAID intake was associated with a protective effect against CRC (RR ranging from 0.57 to 0.74$).{ }^{101516}$ The optimal duration for the observed protective effect of NSAIDs is uncertain, with two meta-analyses suggesting a need for an intake of at least 5 years, ${ }^{10} 16$ whereas the third, suggested a protective effect after the first year. ${ }^{10}$ Moderate to strong heterogeneities were reported in only one meta-analysis. ${ }^{16}$ The level of overall certainty was graded low (table 2).

Summary: Based on observational studies, NSAID use is associated with a significant decrease in CRC incidence, with RR ranging from 0.57 to 0.74 . The effect was consistently significant over $n$ intake of at least 5 years. Certainty of evidence is low.

\section{Magnesium}

Three meta-analyses of observational studies compared the lowest with the highest level of magnesium intake (from dietary sources or supplements). ${ }^{17-19}$ All three meta-analyses found a protective effect against CRC (RR ranging from 0.78 to 0.87$).{ }^{17-19}$ A dose-response analysis was performed in two meta-analyses; one reported a RR of 0.93 (95\% CI 0.88 to 0.99 ) for colon cancer for each incremental intake of $50 \mathrm{mg} /$ day, ${ }^{18}$ whereas the other found no statistically significant differences when assessing $100 \mathrm{mg} /$ day increments, $\mathrm{RR}=0.87$ (95\% CI 0.75 to 1.01$){ }^{17}$

Low to moderate heterogeneity was found within the three meta-analyses. ${ }^{17-19}$ The level of overall certainty was graded low (table 2). 
Recent advances in clinical practice

Table 2 Grading assessment of the certainty of evidence of each component

\begin{tabular}{|c|c|c|c|c|c|c|c|}
\hline \multicolumn{7}{|l|}{ Certainty assessment } & \multirow{2}{*}{$\begin{array}{l}\text { Summary of findings } \\
\text { Relative effect } \\
(95 \% \mathrm{Cl})\end{array}$} \\
\hline No of participants (studies) follow-up & Risk of bias & Inconsistency & Indirectness & Imprecision & Publication bias & Overall certainty of evidence & \\
\hline \multicolumn{8}{|c|}{$\begin{array}{l}\text { Aspirin user compared with non-aspirin user in } \\
\text { prevention of colorectal cancer }\end{array}$} \\
\hline 6 Meta-analyses & Not serious a & Serious b & Not serious C & Not serious & $\begin{array}{l}\text { Publication bias } \\
\text { strongly suspected d }\end{array}$ & $\oplus \oplus \oplus \bigcirc$ Moderate & 0.71 to 0.86 \\
\hline \multicolumn{8}{|c|}{$\begin{array}{l}\text { Low dose aspirin user compared with control in } \\
\text { prevention of colorectal cancer }\end{array}$} \\
\hline 3 Meta-analyses & Not serious & Serious e & Not serious & Not serious & $\begin{array}{l}\text { Publication bias } \\
\text { strongly suspected }\end{array}$ & $\oplus \oplus \bigcirc \bigcirc$ Low & 0.71 to 1.02 \\
\hline \multicolumn{8}{|c|}{$\begin{array}{l}\text { NSAIDs compared with no NSAIDs for prevention } \\
\text { of colorectal cancer }\end{array}$} \\
\hline 3 Meta-analyses & Not serious & Serious $f$ & Not serious & Not serious & $\begin{array}{l}\text { Publication bias } \\
\text { strongly suspected d }\end{array}$ & $\oplus \oplus \bigcirc \bigcirc$ Low & 0.57 to 0.74 \\
\hline \multicolumn{8}{|c|}{$\begin{array}{l}\text { Magnesium compared with control for prevention } \\
\text { of colorectal cancer }\end{array}$} \\
\hline 3 Meta-analyses & Not serious & Not serious & Not serious $\mathrm{g}$ & Not serious & None & $\oplus \oplus \bigcirc \bigcirc$ Low & 0.78 to 0.89 \\
\hline \multicolumn{8}{|c|}{$\begin{array}{l}\text { Folic acid compared with control for prevention of } \\
\text { colorectal cancer }\end{array}$} \\
\hline 3 Meta-analyses & Not serious & Serious $\mathrm{h}$ & serious i & Not serious & $\begin{array}{l}\text { Publication bias } \\
\text { strongly suspected j }\end{array}$ & $\oplus \bigcirc \bigcirc \bigcirc$ Very low & 0.85 to 0.88 \\
\hline \multicolumn{8}{|c|}{$\begin{array}{l}\text { Folic acid in combination with other antioxidants } \\
\text { for the chemoprevention of colorectal cancer }\end{array}$} \\
\hline 3 Meta-analyses & Not serious & Not serious & very serious k & Not serious & None & $\oplus \bigcirc \bigcirc \bigcirc$ Very low & 0.96 to 1.15 \\
\hline \multicolumn{8}{|l|}{$\begin{array}{l}\text { Dairy products compared with control for } \\
\text { prevention of colorectal cancer }\end{array}$} \\
\hline 3 Meta-analyses & Not serious & Serious I & very serious m & Not serious & None & $\oplus \bigcirc \bigcirc \bigcirc$ Very low & 0.81 to 0.87 \\
\hline \multicolumn{8}{|c|}{$\begin{array}{l}\text { Fibre compared with control for prevention of } \\
\text { colorectal cancer }\end{array}$} \\
\hline 5 Meta-analyses & Not serious & Serious $\mathrm{n}$ & very serious $\mathrm{m}$ & Not serious & None & $\oplus \bigcirc \bigcirc \bigcirc$ Very low & 0.57 to 0.94 \\
\hline \multicolumn{8}{|l|}{ Fruits and vegetables } \\
\hline 9 Meta-analyses & Not serious & Serious 0 & very serious $\mathrm{m}$ & Not serious & None & $\oplus \bigcirc \bigcirc \bigcirc$ Very low & 0.48 to 1.00 \\
\hline \multicolumn{8}{|l|}{ Soy products } \\
\hline 3 Meta-analyses & Not serious & Serious $p$ & very serious $\mathrm{m}$ & Not serious & None & $\oplus \bigcirc \bigcirc \bigcirc$ Very low & 0.85 to 1.01 \\
\hline \multicolumn{8}{|l|}{ Vitamin $\mathrm{E}$} \\
\hline 7 Meta-analyses & Not serious & Not serious & serious $\mathrm{m}$ & Not serious & None & $\oplus \oplus \bigcirc \bigcirc$ Low & 0.82 to 1.05 \\
\hline \multicolumn{8}{|l|}{ Vitamin C } \\
\hline 3 Meta-analyses & Not serious & Serious q & Very serious $\mathrm{m}$ & Not serious & None & $\oplus \bigcirc \bigcirc \bigcirc$ Very low & 0.84 to 0.92 \\
\hline \multicolumn{8}{|l|}{$\begin{array}{l}\text { Combinations of vitamins A, C, E, D or } \\
\text { antioxidants }\end{array}$} \\
\hline 5 Meta-analyses & Not serious & Not serious & Very serious $\mathrm{m}$ & Not serious & None & $\oplus \bigcirc \bigcirc \bigcirc$ Very low & 0.92 to 1.00 \\
\hline \multicolumn{8}{|l|}{$\beta$-Carotene } \\
\hline 3 Meta-analyses & Not serious & Serious $r$ & Not serious & Not serious & None & $\oplus \oplus \oplus \bigcirc$ Moderate & 0.99 to 1.09 \\
\hline \multicolumn{8}{|c|}{$\beta$-Carotene in combination with other products } \\
\hline 5 Meta-analyses & Not serious & Not serious & Very serious s & Not serious & None & $\oplus \bigcirc \bigcirc \bigcirc$ Very low & 0.96 to 1.15 \\
\hline \multicolumn{8}{|l|}{ Selenium } \\
\hline 3 Meta-analyses & Not serious & Not serious & Not serious & Not serious & None & $\oplus \oplus \oplus \bigcirc$ Moderate & 0.48 to 0.77 \\
\hline \multicolumn{8}{|l|}{ Tea } \\
\hline 5 Meta-analyses & Not serious & Serious $\mathrm{t}$ & Very serious $\mathrm{m}$ & Not serious & None & $\oplus \bigcirc \bigcirc \bigcirc$ Very low & 0.82 to 0.99 \\
\hline \multicolumn{8}{|l|}{ Garlic } \\
\hline 4 Meta-analyses & Not serious & Serious $\mathrm{u}$ & Very serious $\mathrm{m}$ & Not serious & None & $\oplus \bigcirc \bigcirc \bigcirc$ Very low & 1.03 to 1.24 \\
\hline Vitamin D & & & & & & & \\
\hline 4 Meta-analyses & Not serious & Serious v & Very serious $\mathrm{m}$ & Not serious & None & $\oplus \bigcirc \bigcirc \bigcirc$ Very low & 0.87 to 0.92 \\
\hline 2 Meta-analyses & Not serious & Not serious & Very serious $\mathrm{m}$ & Not serious & None & $\oplus \bigcirc \bigcirc \bigcirc$ Very low & 0.62 to 1.08 \\
\hline Coffee or caffeine & & & & & & & \\
\hline 7 Meta-analyses & Not serious & Serious w & Very serious $\mathrm{m}$ & Not serious & None & $\oplus \bigcirc \bigcirc \bigcirc$ Very low & 0.76 to 1.00 \\
\hline Fish and omega-3 & & & & & & & \\
\hline 7 Meta-analyses & Not serious & Serious $\mathrm{x}$ & Very serious $\mathrm{m}$ & Not serious & None & $\oplus \bigcirc \bigcirc \bigcirc$ Very low & 0.88 to 1.03 \\
\hline Vitamin A & & & & & & & \\
\hline 2 Meta-analyses & Not serious & Not serious & Very serious $\mathrm{m}$ & Not serious & None & $\oplus \oplus \bigcirc \bigcirc$ Low & 0.77 to 0.87 \\
\hline Vitamin B & & & & & & & \\
\hline 2 Meta-analyses & Not serious & Serious y & Very serious $\mathrm{m}$ & Not serious & None & $\oplus \bigcirc \bigcirc \bigcirc$ Very low & 0.86 to 1.18 \\
\hline Calcium & & & & & & & \\
\hline 5 Meta-analyses & Not serious & Serious z & Serious aa & Serious bb & None & $\oplus \bigcirc \bigcirc \bigcirc$ Very low & 0.34 to 1.38 \\
\hline
\end{tabular}


Table 2 Continued

\begin{tabular}{|c|c|c|c|c|c|c|c|}
\hline \multicolumn{7}{|l|}{ Certainty assessment } & \multirow{2}{*}{$\begin{array}{l}\text { Summary of findings } \\
\text { Relative effect } \\
(95 \% \mathrm{Cl})\end{array}$} \\
\hline No of participants (studies) follow-up & Risk of bias & Inconsistency & Indirectness & Imprecision & Publication bias & Overall certainty of evidence & \\
\hline \multicolumn{8}{|l|}{ Statin } \\
\hline 8 Meta-analyses & Not serious & Serious cc & Serious dd & Not serious & None & $\oplus \oplus \bigcirc \bigcirc$ Low & 0.74 to 1.02 \\
\hline \multicolumn{8}{|l|}{ Meat } \\
\hline 7 Meta-analyses & Not serious & Serious ee & Very serious $\mathrm{m}$ & Not serious & None & $\oplus \bigcirc \bigcirc \bigcirc$ Very low & 1.04 to 1.25 \\
\hline \multicolumn{8}{|c|}{$\begin{array}{l}\text { Alcohol compared with control for prevention of } \\
\text { colorectal cancer }\end{array}$} \\
\hline 9 Meta-analyses & Not serious & Serious ff & Serious gg & Not serious & $\begin{array}{l}\text { Publication bias } \\
\text { strongly suspected }\end{array}$ & $\oplus \bigcirc \bigcirc \bigcirc$ Very low & 1.03 to 1.52 \\
\hline
\end{tabular}

a. Source of bias was difficult to assess as included meta-analyses included observational studies and did not perform standard risk of bias tools nor any other biases.

b. Heterogeneity was noted in three of the five meta-analyses ${ }^{910}$ (only for case-control); and ${ }^{11}$, not reported in one ${ }^{13}$ and no heterogeneity noted in one. ${ }^{12}$

c. All meta-analyses, any dose aspirin definition.

d. Publication bias was detected but no value provided in the meta-analysis.

e. Heterogeneity was noted in one of the three meta-analyses, ${ }^{10}$ not reported in two. ${ }^{12} 1$

f. Heterogeneity was noted in one of the three meta-analyses, ${ }^{16}$ not reported in two. ${ }^{10} 15$

g. Intervention and control are based on highest category compared with lowest category of magnesium intake as opposed to primary question, similar quartiles.

h. Heterogeneity reported in one meta-analysis ${ }^{22}$ but not in two others. ${ }^{2021}$

i. Intervention and control are based on different controls as well as high vs low intake.

j. Publication bias was detected in two meta-analyses. ${ }^{2022}$

k. Different intervention and comparison within each meta-analysis included.

I. Heterogeneity found in one meta-analysis. ${ }^{27}$

m. Different intervention and comparison within each meta-analysis included.

n. Heterogeneity was reported in one meta-analysis ${ }^{30}$ none in two $0^{2629}$ and not reported in one. ${ }^{31}$

0 . Varying heterogeneity in meta-analyses.

p. Heterogeneity was noted in Zhu $2015 .^{38}$

q. Strong heterogeneity was reported in one meta-analysis. ${ }^{21}$

r. Two meta-analyses reported heterogeneity ${ }^{42} 46$ and one did not report any results. ${ }^{45}$

s. Different intervention and comparison within each meta-analysis included.

t. Heterogeneity was reported in three meta-analyses ${ }^{2650} 51$ but none in one. ${ }^{48}$

u. Heterogeneity was noted in one meta-analysis ${ }^{54}$.

v. Heterogeneity was reported in two meta-analyses ${ }^{21} 22$ none in one ${ }^{56}$ and not reported in another. ${ }^{55}$

W. Heterogeneity noted in five meta-analyses. ${ }^{58} 60266163$

x. Heterogeneity was noted in three meta-analyses, 656668 none was noted in four. 26336467

y. Heterogeneity was found in one meta-analysis. ${ }^{69}$

z. Heterogeneity was noted in two meta-analyses, ${ }^{21} 73$ none was noted for three. ${ }^{70} 7172$

aa. Intervention and control are based on different controls as well as high vs low intake.

bb. Imprecision due to wide confidence interval in one meta-analysis. ${ }^{70}$

cc. Heterogeneity was reported in two meta-analyses ${ }^{80} 81$ no heterogeneity in two ${ }^{74} 75$ varying strength of heterogeneity between publication type in two ${ }^{77} 78$ or not reported in the last two meta-analyses. ${ }^{76} 79$

dd. Databases used in meta-analyses are population based therefore include all population, not only average-risk population.

ee. Heterogeneity was reported in two meta-analyses, ${ }^{82} 84$ not in five $e^{26} 33398385$.

$\mathrm{ff}$. All included meta-analyses for this outcome reported heterogeneity.

gg. Different intervention and comparison within each meta-analysis included. Doses standard.

Summary: Meta-analyses of observational studies suggest a significant protective effect associated with the highest versus lowest magnesium intake (RR ranging from 0.78 to 0.87 ). The effect was observed when at least $255 \mathrm{mg} /$ day was consumed. Certainty of evidence is low.

\section{Folic acid (vitamin B9)}

Three meta-analyses of observational studies, ${ }^{20-22}$ were reviewed. All compared highest to lowest doses of folate intake, and found total (ie, dietary and supplement) folate intake to be associated with a protective effect against CRC (RR ranging from 0.85 to $0.88){ }^{20-22}$ One meta-analysis provided results by cancer location (rectal or colon) and type of study (cohort or case-control). A protective effect for colon cancer was only described in a pooled analysis of nine cohort studies, $(\mathrm{RR}=0.75 ; 95 \% \mathrm{CI} 0.57$ to 0.99$) .{ }^{20}$ Heterogeneity within the meta-analyses was low, ${ }^{2021}$ to moderate. ${ }^{22}$ The overall certainty of evidence was graded very low.

Three meta-analyses published between 2010 and 2015, two including RCTs exclusively, ${ }^{23} 24$ and one combining RCTs with a cohort study, ${ }^{25}$ have evaluated the effect of folic acid (supplementation of $0.4 \mathrm{mg} /$ day, or 0.5 to $2.5 \mathrm{mg} /$ day) combined with other vitamins or aspirin on CRC incidence (online supplementary table 2). No significant effect on CRC was observed in any of these meta-analyses. Heterogeneity was low in all studies. ${ }^{23-25}$ The level of overall certainty was graded very low.

Summary: Based on meta-analyses of observational studies, high intake of folic acid is associated with a significant decrease in CRC risk $(\mathrm{RR}=0.85$ to 0.88$)$. A protective dose cannot be determined. However, meta-analyses of RCTs investigating folate in combination with various other components did not report any effect on CRC incidence. Certainty of evidence is very low.

\section{Dairy products}

Three meta-analyses of observational studies, published between 2012 and 2017, were included. ${ }^{26-28}$ Results are presented below according to the type of dairy products investigated.

Aune $e$ t $a l^{27}$ reported a RR for CRC of 0.81 (95\% CI 0.74 to $0.90)$ associated with high versus low consumers of dairy products. The effect appeared to be dose related, with any $400 \mathrm{~g} /$ day increase being associated with a RR reduction of $0.83-0.87 . .^{26} 27$

The protective effect persisted when the analysis was restricted to milk consumption, both for CRC as a whole $(\mathrm{RR}=0.83$; $95 \%$ CI 0.74 to 0.93$)$ and colon cancer in particular $(\mathrm{RR}=0.82$; $95 \%$ CI 0.72 to 0.94$)$, but not rectal cancer. ${ }^{27} \mathrm{~A}$ similar protective effect against $\mathrm{CRC}(\mathrm{RR}=0.85$; 95\% CI 0.77 to 0.93$)$ was reported in high consumers of non-fermented milk. ${ }^{28}$ The effect was statistically significant in men $(\mathrm{RR}=0.79$; 95\% CI 0.69 to $0.93)$ but not in women $(\mathrm{RR}=0.83 ; 95 \% \mathrm{CI} 0.68$ to 1.02$) .{ }^{28}$ In a dose-response analysis, RRs ranged from 0.90 to 0.94 for CRC and from 0.92 to 0.93 for colon cancer alone, both for a $200 \mathrm{~g} /$ day increase of milk consumption. ${ }^{26}{ }^{27}$ For rectal cancer, only one of the two meta-analyses showed a statistically significant protective effect $(\mathrm{RR}=0.94 ; 95 \% \mathrm{CI} 0.91$ to 0.97$) .^{27}$ 
None of the meta-analyses described a protective effect associated with cheese consumption. ${ }^{26-28}$

Heterogeneity was low to moderate in all the meta-analyses. The level of overall certainty was graded very low.

Summary: Based on observational studies, consumption of dairy products is associated with a decrease in CRC risk $(\mathrm{RR}=0.81$ to 0.87$)$. However, the small number of available meta-analyses, and the multiplicity of outcomes and variety of dairy products do not allow any confident conclusion to be reached about dose or duration necessary for protection. Certainty of evidence is very low.

\section{Fibres}

Five meta-analyses of observational studies published between 1990 and 2018 were included. ${ }^{2629-32}$

The highest intakes of total dietary fibres showed a protective effect against CRC (RR ranging from 0.57 to 0.88). ${ }^{29} 30$ One meta-analysis focused on colon cancer only and also reported a significant protective effect $(\mathrm{RR}=0.82 ; 95 \% \mathrm{CI} 0.73$ to 0.92$) .{ }^{32}$ Each incremental $10 \mathrm{~g} /$ day of whole grain consumption was associated with a significant risk reduction in both CRC (RR ranging from 0.83 to 0.90$),{ }^{26} 29$ and colon cancer $(\mathrm{RR}=0.82 ; 95 \% \mathrm{CI}$ 0.73 to 0.92$).{ }^{26}$ Significant heterogeneity was reported in three studies. ${ }^{293032}$ The level of overall certainty was graded very low.

Summary: Based on observational studies, fibre consumption is associated with a significant reduction in CRC risk, ranging from 0.57 to 0.78 . Nevertheless, optimal daily dose and duration of intake cannot be defined due to significant heterogeneity across studies. Certainty of evidence is very low.

\section{Fruits and vegetables}

Nine meta-analyses published from 1990 to 2017, all of observational studies only, were included. ${ }^{263033-39}$ Results are presented below according to the type of fruit and/or vegetable investigated.

Considered altogether, high consumption of fruits and vegetables was associated with a significant decreased risk in both colorectal $(\mathrm{RR}=0.92 ; 95 \% \mathrm{CI} 0.86$ to 0.99$)$ and colon $(\mathrm{RR}=0.91 ; 95 \% \mathrm{CI} 0.84$ to 0.99$)$ cancers in one meta-analysis. ${ }^{34}$

High fruit consumption was associated with a protective effect for both CRC $(\mathrm{RR}=0.90 ; 95 \% \mathrm{CI} 0.83$ to 0.98$)$ and colon cancer $(\mathrm{RR}=0.89 ; 95 \% \mathrm{CI} 0.81$ to 0.98$)$, but not for rectal cancer $(\mathrm{RR}=0.91 ; 95 \% \mathrm{CI} 0.76$ to 1.09$) .{ }^{34}$ Conflicting results were reported by Huxley et al, where the only significant effect was found for rectal cancer $(\mathrm{RR}=0.78 ; 95 \% \mathrm{CI} 0.63$ to 0.97$)$, but not colorectal $(\mathrm{RR}=0.99 ; 95 \% \mathrm{CI} 0.90$ to 1.08$)$ or colon cancer $(\mathrm{RR}=1.01 ; 95 \% \mathrm{CI} 0.86 ; 1.18)$. $^{33}$

Three of six meta-analyses reported a significantly decreased CRC risk in those having high vegetables intake, ${ }^{30} 3437$ (RR ranging from 0.48 to 0.91 ); the other three meta-analyses found no statistically significant effects. ${ }^{33} 3639$ Two of the four metaanalyses reported significant protective effects for colon cancer (RR ranging from 0.84 to 0.87 ), ${ }^{3436}$ but none for rectal cancer.

A significant dose-effect against CRC was found for any $100 \mathrm{~g} /$ day incremental fruit and vegetable intake $(\mathrm{RR}=0.98$; $95 \%$ CI 0.97 to 0.99$)$, and for vegetable intake only $(\mathrm{RR}=0.90$; $95 \%$ CI 0.85 to 0.95$),{ }^{34}$ (RR $=0.98 ; 95 \%$ CI 0.96 to 0.99$) .{ }^{26}$ For the fruit consumption dose-effect analysis, controversial results have been reported. Indeed, a significant dose-effect for any increment of $100 \mathrm{~g} /$ day was reported by Aune et $a l^{34}$ ( $R R=0.89$; $95 \%$ CI 0.81 to 0.98 ), whereas results from Vieira et $a l^{26}$ failed to reach statistical significance either for CRC, colon cancer or rectal cancer.
High consumption of legume, cabbage and cruciferous vegetables was associated with a significantly decreased CRC risk (RR ranging from 0.76 to 0.91$).{ }^{35} 38$ However, no effect was found in the dose-response analysis for legume consumption. ${ }^{26}$

Heterogeneity was reported to be low to moderate, ${ }^{2635-39}$ or low. ${ }^{30} 3334$ The overall level of certainty was graded very low.

Summary: Several meta-analyses of observational studies suggest a protective effect of fruit and/or vegetable consumption against CRC risk, with RR ranging from 0.48 to 0.92 , with also an incremental benefit for any $100 \mathrm{~g} /$ day incremental intake. More specific conclusions about type, dose and duration cannot be made. Certainty of evidence is very low.

\section{Soy}

Three meta-analyses of observational studies were published between 2014 and 2016. ${ }^{38-40}$ A significant protective effect of soy or soybean consumption against CRC was reported in two metaanalyses $(\mathrm{RR}=0.85 ; 95 \% \mathrm{CI} 0.73$ to 0.99$),{ }^{38}$ and $(\mathrm{OR}=0.92 ; 95 \%$ CI 0.87 to 0.97$)^{40}$, whereas another reported no significant effect. ${ }^{39}$ The noted beneficial effect was significant for colon $(\mathrm{OR}=0.92$; $95 \%$ CI 0.96 to 0.99 ) but not rectal cancer. ${ }^{40}$

Heterogeneity was low to moderate. ${ }^{3840}$ The level of overall certainty was graded very low.

Summary: Observational studies suggest a modest but significant decrease in colon cancer risk associated with soy consumption $(\mathrm{RR}=0.85$ to 0.92$)$. Certainty of evidence is very low

\section{Components with no protective effect on CRC prevention (SUPPLEMENTARY TABLE 2)}

\section{Vitamin E}

Seven meta-analyses, five including RCTs only, ${ }^{41-45}$ and two comprising cohort studies, ${ }^{21} 22$ were published between 2007 and 2015, investigating the effects of vitamin E consumption on CRC risk.

None of the studies reported any significant effect of vitamin E intake on CRC. Only one meta-analysis of five cohort studies comparing highest with lowest intake reported a significant protective effect against colon cancer $(\mathrm{RR}=0.82 ; 95 \% \mathrm{CI} 0.67$ to 0.99$).{ }^{21}$ Heterogeneity was low to moderate in all the metaanalyses. The level of overall certainty was graded low.

Summary: RCT and observational studies suggest that vitamin E supplementation is not protective for CRC. Certainty of evidence is low.

\section{Vitamin C}

Three meta-analyses, two of observational studies only, ${ }^{21} 22$ and one of RCTs, ${ }^{44}$ published between 2011 and 2015, investigated the effect of vitamin $\mathrm{C}$ consumption on CRC prevention.

No protective effect of vitamin $\mathrm{C}$ intake on CRC or colon cancer risk was shown in any of the meta-analyses. ${ }^{21} 2244$

Heterogeneity was low in the study by Papaioannou et al, ${ }^{44}$ moderate in Liu et $a l,{ }^{22}$ and strong in Heine-Bröring et al. ${ }^{21}$ The level of overall certainty was graded very low.

Summary: RCT and observational studies do not suggest a protective effect of vitamin $\mathrm{C}$ in CRC prevention. Certainty of evidence is very low

\section{Antioxidants combination or combination of vitamins with other} components

Five meta-analyses, four of RCTs only, ${ }^{41424445}$ and one of cohort studies, ${ }^{21}$ were published between 2007 and 2015. These investigated antioxidants or vitamin combinations with other components. 
Only one of these five meta-analyses reported a significant protective effect of multivitamin supplementation on CRC risk $(\mathrm{RR}=0.92 ; 95 \%$ CI 0.86 to 0.98$) .^{21}$

Heterogeneity was low in four of the meta-analyses, 21424445 and not reported in the fifth. ${ }^{41}$ The level of overall certainty was graded very low.

Summary: RCT and observational studies do not suggest that multivitamin intake, either alone or in combination with other components, exerts a protective effect on CRC risk. Certainty of evidence is very low.

\section{$\beta$-Carotene}

Eight meta-analyses of RCT published between 2004 and 2013 have been included. Among them, three assessed $\beta$-carotene alone $^{424546}$ and five $\beta$-carotene in combination with other supplements or medication, including aspirin and various 'other components' (such as vitamin C, selenium or vitamin E). ${ }^{42} 44-47$

None of the pooled analyses, overall or by subgroups (according to gender or incremental dosing), found any significant protective effect of $\beta$-carotene consumption alone, or in association with other agents, on CRC risk.

Heterogeneity was strong in one study, ${ }^{46}$ moderate in two others, ${ }^{4244}$ and not provided in the two others. ${ }^{45} 47$ The level of overall certainty was graded moderate for $\beta$-carotene alone and very low for $\beta$-carotene in combination.

Summary: Meta-analyses of RCTs provide no evidence to support the use of $\beta$-carotene, either alone or in combination with other products, in the primary prevention of CRC. Certainty of evidence is moderate for $\beta$-carotene alone and very low for $\beta$-carotene in combination.

\section{Selenium}

The effect of selenium supplementation on CRC risk was assessed in three meta-analyses of RCTs. ${ }^{42} 4445$

None of the meta-analyses showed any significant effect of selenium on CRC incidence, either taken alone or in combination with other agents.

Heterogeneity was moderate in Papaioannou et al, ${ }^{44}$ low in Pais $e t a l^{45}$ and not assessed in the Bjelakovic et $a l .{ }^{42}$ The level of overall certainty was graded moderate.

Summary: Meta-analytical data of RCT suggest no protective effect of selenium on CRC risk. Certainty of evidence is moderate.

\section{Products noted to have an unclear effect on CRC prevention (SUPPLEMENTARY TABLE 3)}

Tea

Five meta-analyses of observational studies published between 2006 and 2017 were reviewed. ${ }^{2648-51}$

Overall, high tea consumption (green, black and mixed tea) was not associated with a significant protective effect for CRC in two meta-analyses. ${ }^{49} 50$ Two meta-analyses investigated he effect of green tea consumption on CRC risk, with the first reporting a significant effect, ${ }^{51}$ but not the second. ${ }^{48}$

In subsite analysis, the protective effect was found in rectal cancer only $(\mathrm{OR}=0.91 ; 95 \% \mathrm{CI} 0.85$ to 0.99$) .{ }^{50}$ In gender subgroup analysis, high consumption of tea and black tea (1 to 5 cups/day) were both reported to be protective against CRC in women $\left(\mathrm{OR}=0.86 ; 95 \% \mathrm{CI} 0.78\right.$ to $0.94^{50}$ and $\mathrm{OR}=0.82$; $95 \%$ CI 0.70 to $0.95,{ }^{51}$ for any type of tea and black tea, respectively). In the three remaining meta-analyses, no protective effect of tea consumption was reported. ${ }^{264849}$
Heterogeneity was moderate in three studies, ${ }^{48-50}$ strong in one $^{26}$ and significant in the last two. ${ }^{42}$ The level of overall certainty was graded very low.

Summary: Conclusions from meta-analyses of observational studies are disparate, with the effect of tea consumption on CRC risk remaining unclear. Certainty of evidence is very low.

\section{Allium and garlic}

Four meta-analyses of observational studies, published between 2013 and 2014, investigated the role of allium vegetable, and garlic consumption, or garlic supplementation in CRC prevention. $^{2152-54}$

When the effect of allium and garlic as a whole was assessed, no protective effect was reported. However, when studied separately, one meta-analysis found that garlic and onion consumption were both associated with a significant CRC risk reduction $(\mathrm{RR}=0.76 ; 95 \% \mathrm{CI} 0.67$ to 0.85 and $\mathrm{RR}=0.74 ; 95 \% \mathrm{CI} 0.56$ to 0.98 , for garlic and onion, respectively), and garlic alone with a decreased incidence of rectal cancer $(\mathrm{RR}=0.76 ; 95 \% \mathrm{CI}$ 0.59 to 0.98$).{ }^{54}$ Study heterogeneity was moderate in one metaanalysis, ${ }^{54}$ and low in the others. ${ }^{215253}$ The level of overall certainty was graded very low.

Summary: Meta-analyses of observational studies yield disparate results to support any protective effect of allium and garlic consumption on CRC incidence. Certainty of evidence is very low.

\section{Vitamin D}

Four meta-analyses, published between 2011 and 2015, evaluated the effect of vitamin D on CRC prevention. One included RCTs only, ${ }^{55}$ and three assessed observational studies only. ${ }^{21} 2256$

Two of the meta-analyses of observational studies, comparing the highest with the lowest range of vitamin $\mathrm{D}$ intake, reported significant CRC risk reductions (RR ranging from 0.87 to $0.88) .^{22} 56$ Conversely, no significant protective effect was reported by the third meta-analysis of observational studies, ${ }^{21}$ nor the meta-analysis of RCTs only. ${ }^{55}$

None of two meta-analyses of RCT investigating the combination of vitamin $\mathrm{D}$ and calcium reported a significant protective effect on CRC incidence. ${ }^{55} 57$

Heterogeneity was low ${ }^{56}$ to moderate, ${ }^{21} 2257$ or not reported in one meta-analysis. ${ }^{55}$ The level of overall certainty was graded very low.

Summary: Meta-analyses of RCTs and observational studies yield disparate results to support any protective effect for vitamin $\mathrm{D}$ alone or in combination with calcium in CRC prevention. Certainty of evidence is very low.

\section{Coffee and caffeine}

Seven meta-analyses of observational studies, published between 1998 and 2017, assessed coffee or caffeine intake and CRC risk. $^{2658-63}$

Four of the seven meta-analyses reported no significant protective effect associated with coffee consumption on CRC risk. $^{265961-63}$ Two others reported a significant decrease in CRC risk among drinkers versus no drinkers $(\mathrm{OR}=0.83 ; 95 \% \mathrm{CI}$ 0.73 to 0.95$),{ }^{60}$ or drinkers of greatest versus lowest volumes $(\mathrm{RR}=0.76 ; 95 \% \mathrm{CI} 0.66$ to 0.89$) .{ }^{58}$ The seventh meta-analysis by $\mathrm{Li}$ et $a l^{61}$ reported a significant protective association for the colon cancer subgroup $(\mathrm{OR}=0.79 ; 95 \% \mathrm{CI} 0.67$ to 0.95$)$, whereas the effect was not significant in rectal cancer.

Among the three meta-analyses that performed a doseresponse analysis, ${ }^{26} 6063$ one reported a protective association 
for an incremental consumption of $1 \mathrm{cup} /$ day on CRC, as well as on colon and rectal cancer when analysed individually (OR ranging from 0.94 to 0.97$).{ }^{60}$ The second reported a protective association for an incremental consumption of 6 to 8 cups/ day (RR ranging from 0.87 to 0.93 ), ${ }^{63}$ while the third found no significant association. ${ }^{26}$

Heterogeneity was low in one meta-analysis, ${ }^{59}$ moderate in three, ${ }^{266163}$ high in two meta-analyses ${ }^{5860}$ and not reported in the last study. ${ }^{62}$ The level of overall certainty was graded very low.

Summary: Meta-analyses of observational studies and sitespecific subgroup analyses yield disparate results for any protective effect for coffee and caffeine intake in CRC prevention. Certainty of evidence is very low.

\section{Fish and omega-3}

Seven meta-analyses of observational studies published between 2007 and 2017 were reviewed. ${ }^{263364-68}$

In two of these, fish consumption was associated with a significant CRC risk reduction (RR ranging from 0.87 to 0.93 ) compared with non-/lowest-consumers. ${ }^{65} 68$ A protective effect was also observed for rectal cancer $(\mathrm{RR}=0.79$; 95\% CI 0.65 to 0.97 and $\mathrm{RR}=0.85 ; 95 \% \mathrm{CI} 0.75$ to 0.95$),{ }^{65} 68$ and colon cancer alone $(\mathrm{RR}=0.95 ; 95 \% \mathrm{CI} 0.91$ to 0.98$) .{ }^{68} \mathrm{In}$ a third meta-analysis, the results were significant when assessing the pooled results of case-control studies (OR 0.83 to 0.84 ) but not of cohort studies. ${ }^{67}$ Three other meta-analyses did not report any significant associations when comparing highest and lowest consumption of fish or omega-3 fatty acids. ${ }^{336466}$ In a doseresponse analysis of the seventh meta-analysis, any incremental $100 \mathrm{mg} /$ day of fish consumption was associated with a significant decrease in CRC risk ( $R R=0.89 ; 95 \%$ CI 0.80 to 0.99$)$, but the protective effect was lost when colon or rectal cancers were assessed separately. ${ }^{26}$ None of the other meta-analyses reporting incremental levels of fish consumption $(20 \mathrm{~g} /$ day once a week and $100 \mathrm{~g} /$ week) found any significant dose-response protective effects on CRC. ${ }^{6468}$

Heterogeneity was low in four meta-analyses, ${ }^{26} 33 \quad 6467$ moderate in two ${ }^{6668}$ and significant in the last. ${ }^{65}$ The level of overall certainty was graded very low.

Summary: Meta-analyses of observational studies and sitespecific subgroup analyses yield disparate results to support any protective effect for fish and omega-3 consumption in CRC prevention. Certainty of evidence is very low.

\section{Vitamin A}

Two meta-analyses of observational studies evaluating the association between vitamin A consumption and CRC, ${ }^{22}$ or colon cancer risk, ${ }^{21}$ were published in 2015.

No significant association was found when comparing low intake with high intake of vitamin A either for CRC or colon cancer sites. ${ }^{2122}$ However, a significant protective association for colon cancer was found when comparing any vitamin A consumption with no intake $(\mathrm{RR}=0.77 ; 95 \% \mathrm{CI} 0.62$ to $0.94) .^{21}$

There was no heterogeneity in any of the meta-analyses. The level of overall certainty was graded low.

Summary: Two meta-analyses of observational studies yielded inconsistent results when assessing any protective effect of vitamin A intake in CRC chemoprevention. Certainty of evidence is low.
Vitamin B group (folic acid excluded)

Two meta-analyses of observational studies, published in 2010 and 2015, were reviewed, one assessing intake of vitamin B2, vitamin $\mathrm{B} 3$, vitamin $\mathrm{B} 6$ and vitamin $\mathrm{B} 12,{ }^{22}$ while the second focused exclusively on vitamin B6 intake. ${ }^{69}$ The first metaanalysis compared highest with lowest intake, and noted that vitamin $\mathrm{B} 2$ and vitamin $\mathrm{B} 6$ were associated with a decreased risk of $\mathrm{CRC}(\mathrm{RR}=0.86 ; 95 \% \mathrm{CI} 0.76$ to 0.97 and $\mathrm{RR}=0.88 ; 95 \% \mathrm{CI}$ 0.79 to 0.99 for vitamins B2 and B6, respectively). ${ }^{22}$ The second meta-analysis did not suggest any protective effect associated with vitamin $\mathrm{B} 6$ consumption. ${ }^{69}$

Heterogeneity was reported as moderate, ${ }^{22}$ or strong. ${ }^{69}$ The level of certainty was graded very low.

Summary: Two meta-analyses of observational studies yielded inconsistent results for any protective effect of the intake of vitamins B in CRC chemoprevention. Certainty of evidence is very low.

\section{Calcium}

Five meta-analyses published between 2008 and 2015 were reviewed, two of RCTs only, ${ }^{70}$ and three of observational studies. $^{217273}$

No significant effect of overall calcium supplementation on CRC incidence was reported in the meta-analyses that included two RCTs, ${ }^{70}$ and seven $\mathrm{RCTs}^{71}$ (study-level analysis), but an increased CRC risk $(\mathrm{HR}=1.63 ; 95 \% \mathrm{CI} 1.01$ to 2.64$)$ was reported in patients receiving more than $500 \mathrm{mg} /$ day of calcium supplementation in the results of four RCTs at a patientlevel analysis. ${ }^{71}$ In contrast, a significant protective association was reported in two meta-analyses of observational studies $(\mathrm{RR}=0.76 ; 95 \% \mathrm{CI} 0.65$ to 0.89$)$ and $(\mathrm{RR}=0.86 ; 95 \% \mathrm{CI}$ 0.79 to 0.95$).{ }^{2172}$ An association with decreased CRC risk was noted for calcium dose ingestion for every $300 \mathrm{mg} /$ day increase $(\mathrm{RR}=0.91 ; 95 \% \mathrm{CI} 0.86$ to 0.98$) .^{73}$

Heterogeneity was moderate in two meta-analyses, ${ }^{21} 73$ and low in the others. ${ }^{70-72}$ The level of overall certainty was graded very low.

Summary: Although a modest protective effect on CRC incidence was found in observational studies of increased calcium ingestion, no protective effect, and even an increased CRC risk was reported in a meta-analysis of RCTs. Certainty of evidence is very low.

\section{Statins}

Eight meta-analyses, published between 2006 and 2014 were reviewed, one of RCT only, ${ }^{74}$ two of observational studies only $^{75}{ }^{76}$ and five that included RCTs and observational studies. $^{77-81}$

None of the meta-analyses with pooled results of RCTs reported any significant protective effect of statin consumption on CRC incidence as compared with placebo or no treatment. ${ }^{747577788081}$ In contrast, significant risk reductions of CRC were observed in pooled results of meta-analyses assessing only case-control or cohort studies (RR ranging from 0.86 to 0.92). ${ }^{77} 788081$ and in pooled results grouping both RCTs and observational studies (RR 0.90 and 0.91). ${ }^{8081}$

Heterogeneity was low to moderate in the pooled analyses of RCTs, ${ }^{747778} 8081$ while moderate or strong heterogeneity was reported in the meta-analyses comprising observational studies, ${ }^{75} 788081$ except for one reporting low heterogeneity. ${ }^{77}$ The level of overall certainty was graded low.

Summary: Disparate evidence exists for any protective effect of statin administration on CRC risk. Although meta-analyses of 
observational studies suggest a protective association, no beneficial effect was noted in meta-analyses of RCTs. Certainty of evidence is low.

\section{Products yielding a consistent increased risk of CRC (SUPPLEMENTARY TABLE 4)}

Meat

Seven meta-analyses of observational studies, published between 2001 and 2017, assessed meat/fat animal consumption on CRC risk. $^{2633} 3982-85$

A large amount of meat consumption and incremental $100 \mathrm{~g} /$ day of total meat consumption were both significantly associated with an increased CRC risk (RR ranging from 1.21 to 1.25 ). ${ }^{39} 82$

High versus low red meat intake was significantly associated with increased CRC risk (RR ranging from 1.12 to 1.21 ). ${ }^{26338485}$ A similar effect was also reported for incremental intakes of $100 \mathrm{~g} /$ day of red meat, and for each incremental serving of meat per day $(\mathrm{RR}=1.12 ; 95 \% \mathrm{CI} 1.00$ to 1.25$),{ }^{26} \mathrm{OR}=1.30 ; 95 \%$ CI 1.13 to 1.49$),{ }^{82}$ and each incremental serving per week $\left(\mathrm{SRRE}=1.02 ; 95 \%\right.$ CI 1.00 to $\left.1.04^{84}\right)$. An increased association with colon cancer was also noted (RR ranging from 1.11 to 1.22), ${ }^{26338485}$ whereas only one meta-analysis suggested such a deleterious association for rectal cancer $(\mathrm{RR}=1.28 ; 95 \%$ CI 1.02 to 1.60$).^{33}$

In two meta-analyses a significantly increased association was reported between processed meat consumption and CRC $\left(R R=1.17\right.$ to $\left.1.19^{33} 85\right)$, or colon cancer risks $(R R=1.21$ to $1.23)^{33} 85$. Each incremental intake of $50 \mathrm{~g}$ /day of processed meat led to significant increases in CRC, colon and rectal cancer risks (RR ranging from 1.08 to 1.23), the magnitude of the association being greatest for colon cancer. ${ }^{26}$

In contradiction to red and processed meat consumption, a significant risk reduction in rectal cancer $(\mathrm{RR}=0.80 ; 95 \% \mathrm{CI}$ 0.67 to 0.96 ) was reported for high versus low consumers of poultry. ${ }^{85}$ No dose-effect was found in the meta-analysis by Vieira et $a l^{26}$ for any of cancer location.

No significant effect was reported with animal fat or protein intake. $^{83}$

Heterogeneity was low to moderate in two meta analyses ${ }^{26} 39$ and reported as 'significant' in two others. ${ }^{8284}$ The level of overall certainty was graded very low.

Summary: Most of the available meta-analyses of observational studies report a significant association (RR ranging from 1.12 to 1.21 ) between meat consumption (particularly red and processed) and increased CRC incidence. Dose-effect studies report a $10-30 \%$ increased risk for each increment of $100 \mathrm{~g}$ /day of total or red meat, with no clear limit threshold identifiable. Certainty of evidence is very low.

\section{Alcohol}

Nine meta-analyses of observational studies, published between 1990 and 2015, were reviewed. ${ }^{86-94}$

Three meta-analyses comparing no/occasional drinkers with regular drinkers showed a significant increase in CRC risk (RR ranging from 1.12 to 1.20). ${ }^{909394}$ Investigating a dose-effect and considering the no/occasional drinkers as controls, the lowest ingestion category of drinking ( $\leq 1 \mathrm{drink} /$ day) was associated with a modest but significant increase in $\mathrm{CRC}$ risk $(\mathrm{RR}=1.07$; $95 \%$ CI 1.02 to 1.13 ) in one meta-analysis. ${ }^{93}$ A clear dose-effect relationship was reported in the meta-analysis of Bagnardi et al, ${ }^{88}$ in which the RR for CRC increased with alcohol consumption (from 1.08 to 1.38 for daily intake of $25 \mathrm{~g}$ to $100 \mathrm{~g}$, respectively).
For moderate drinkers (daily intake of two drinks, up to $25 \mathrm{~g} /$ day of alcohol), two meta-analyses reported a significant association between alcohol intake and CRC risk (RR from 1.08 to 1.10). ${ }^{8688}$ With intakes of $2-3$ drinks/day (12.6g/day) up to $50 \mathrm{~g} /$ day, all meta-analyses consistently reported a significant increase of CRC risk (RR between 1.17 and 1.23).88909293

Higher relative risks were reported in the highest exposure categories (heavy drinkers $>4$ drinks/day, more than $50 \mathrm{~g} /$ day) (RR ranging from 1.38 to 1.53$) .{ }^{8890} 92-94$ The relative risk for rectal cancer tended to be greater than for colon cancer. ${ }^{86-94}$

When stratified by gender, significant increases in CRC risk were observed for men only. ${ }^{90}$ When assessed, the risk for CRC in men increased proportionally to the amount of alcohol intake. $^{909293}$

Heterogeneity was moderate or 'significant' in all the metaanalyses. ${ }^{86-94}$ The level of overall certainty was graded very low.

Summary: Alcohol intake is associated with a significantly increased risk of CRC. The effect is dose-dependent and appears even at the lowest consumption doses investigated (1-2 drinks/ day). For similar intakes, men tend to have greater CRC risk. Certainty of evidence is very low.

\section{CONCLUSIONS}

This contemporary umbrella review has confirmed decreased CRC incidences associated with some CRC chemopreventive agents, such as aspirin, NSAIDS, magnesium, folate, dairy products, fibre, soy or fruits and vegetables, suggesting that their use should be encouraged to reduce CRC incidence in average-risk individuals. On the other hand, meat consumption and alcohol intake were associated with increased CRC risks in almost all the meta-analyses published. Nevertheless, it should be kept in mind that the level of evidence is low or very low in most cases, mainly due to marked heterogeneity across published studies, and the type of study. Furthermore, in most cases, we were unable to identify an optimal dose and duration of exposure/intake for any of the products, even in the case of lowdose aspirin and other compounds that have been extensively assessed. Although the present study synthesises the available data in the literature for chemoprevention of CRC, even in the case where all the meta-analyses provide congruent data (going in the same direction, whether protective or deleterious for the occurrence of (RC), the aforementioned limitations prevent us from providing high level of evidence for the consumption of any of the medications, vitamins, supplements and dietary factors discussed.

Since colorectal carcinogenesis is a process that spans several years or decades, ${ }^{95}$ designing RCTs specifically to assess the prevention of CRC in an average-risk population may not be feasible, and the effects of many molecules and foods can be studied only using long-term follow-up cohorts or case control studies - and this despite the difficulties in adjusting for many confounders as is needed in these types of studies that are more subject to bias. Additionally, in most of the RCTs, CRC incidence was usually not the primary endpoint of the trial (probably owing to feasibility and sample size considerations), while the populations investigated probably do not reflect a true general population, as patients known to be at a greater risk were often excluded.

The adverse events implications of any recommendations for large populations need also be considered and may outweigh benefits with regards to CRC incidence, such as has been the case in guidelines that have moved away from primary prevention of cardiovascular disease using ASA. ${ }^{96}$ 
We were not able to identify any subgroups in the general population that would particularly benefit or suffer from a particular chemopreventive agent owing to the average-risk population targeted, and the source data availability of stratified analyses above and beyond what we report.

One major limitation of the present umbrella meta-analysis was the impossibility of pooling the results of the different metaanalyses included for each component because of high betweenstudy heterogeneity for patient selection, dosing and duration of exposure or intervention, follow-up time, and type of molecule/ food investigated. Although we proceeded systematically for every agent, grading of the evidence is usually performed for meta-analyses based on pooled estimates and therefore was not fully applicable in the present case. It is important for readers to understand that we completed an umbrella meta-analysis of published meta-analyses. We did not perform a systematic review of recent RCTs which may have been published after the end date of our literature review (2019).

It is our hope that despite all aforementioned limitations, this comprehensive umbrella meta-analysis will assist clinicians in counselling patients, and help to guide the future research on the topic that is required in many instances, to better characterise the impact of a nutritional, supplement, or chemical intervention in CRC prevention in an average-risk population.

\section{Twitter Marc Bardou @mbardou}

Acknowledgements ANB is the holder of the DG Kinnear Chair in Gastroenterology at McGill University. Writing assistance was funded by the Direction of Clinical Research and Innovation (DRCI) of Dijon-Bourgogne University Hospital.

Contributors $\mathrm{MB}$ and $\mathrm{MM}$ carried out the literature search and selection, $\mathrm{NC}$ and MM extracted the data, NC, MB and MM drafted the manuscript. ANB reviewed the data extraction, ANB and ET-Z provided a scientific assessment and substantially contributed to manuscript preparation, for initial and revised submissions.

Funding The authors have not declared a specific grant for this research from any funding agency in the public, commercial or not-for-profit sectors.

Competing interests None declared.

Patient and public involvement Patients and/or the public were not involved in the design, or conduct, or reporting, or dissemination plans of this research.

Patient consent for publication Not required.

Provenance and peer review Not commissioned; externally peer reviewed.

Open access This is an open access article distributed in accordance with the Creative Commons Attribution Non Commercial (CC BY-NC 4.0) license, which permits others to distribute, remix, adapt, build upon this work non-commercially, and license their derivative works on different terms, provided the original work is properly cited, appropriate credit is given, any changes made indicated, and the use is non-commercial. See: http://creativecommons.org/licenses/by-nc/4.0/.

\section{ORCID iDs}

Nicolas Chapelle http://orcid.org/0000-0003-4834-9693

Alan N Barkun http://orcid.org/0000-0002-1798-5526

Marc Bardou http://orcid.org/0000-0003-0028-1837

\section{REFERENCES}

1 Siegel RL, Miller KD, Jemal A, et al. Cancer statistics 2019. CA Cancer J Clin 2018:7-30.

2 Andrieu N, Launoy G, Guillois R, et al. Familial relative risk of colorectal cancer: a population-based study. Eur J Cancer 2003;39:1904-11.

3 Arnold M, Sierra MS, Laversanne M, et al. Global patterns and trends in colorectal cancer incidence and mortality. Gut 2017;66:683-91.

4 Arber N, Levin B. Chemoprevention of colorectal neoplasia: the potential for personalized medicine. Gastroenterology 2008;134:1224-37.

5 Hewitson P, Glasziou P, Irwig L, et al. Screening for colorectal cancer using the faecal occult blood test, Hemoccult. Cochrane Database Syst Rev 2007;348:CD001216.

6 Toes-Zoutendijk E, Portillo I, Hoeck S, et al. Participation in faecal immunochemical testing-based colorectal cancer screening programmes in the northwest of Europe. J Med Screen 2019;969141319879712.
7 de Klerk CM, Gupta S, Dekker E, et al. Socioeconomic and ethnic inequities within organised colorectal cancer screening programmes worldwide. Gut 2018;67:679-87.

8 Guyatt GH, Oxman AD, Vist GE, et al. Grade: an emerging consensus on rating quality of evidence and strength of recommendations. BMJ 2008:336:924-6.

9 Bosetti C, Gallus S, La Vecchia C. Aspirin and cancer risk: an updated quantitative review to 2005. Cancer Causes Control 2006;17:871-88.

10 Din FVN, Theodoratou E, Farrington SM, et al. Effect of aspirin and NSAIDs on risk and survival from colorectal cancer. Gut 2010:59:1670-9.

11 Bosetti C, Rosato V, Gallus S, et al. Aspirin and cancer risk: a quantitative review to 2011. Ann Oncol 2012;23:1403-15.

12 Ye X, Fu J, Yang Y, et al. Dose-risk and duration-risk relationships between aspirin and colorectal cancer: a meta-analysis of published cohort studies. PLoS One 2013:8:e57578.

13 Dubé C, Rostom A, Lewin G, et al. The use of aspirin for primary prevention of colorectal cancer: a systematic review prepared for the U.S. preventive services task force. Ann Intern Med 2007;146:365-75.

14 Emilsson L, Holme Ø., Bretthauer M, et al. Systematic review with meta-analysis: the comparative effectiveness of aspirin vs. screening for colorectal cancer prevention. Aliment Pharmacol Ther 2017:45:193-204.

15 Rostom A, Dubé C, Lewin G, et al. Nonsteroidal anti-inflammatory drugs and cyclooxygenase-2 inhibitors for primary prevention of colorectal cancer: a systematic review prepared for the U.S. preventive services Task force. Ann Intern Med 2007; 146:376-89.

16 Tomić T, Domínguez-López S, Barrios-Rodríguez R. Non-aspirin non-steroidal antiinflammatory drugs in prevention of colorectal cancer in people aged 40 or older: a systematic review and meta-analysis. Cancer Epidemiol 2019;58:52-62.

17 Wark PA, Lau R, Norat T, et al. Magnesium intake and colorectal tumor risk: a casecontrol study and meta-analysis. Am J Clin Nutr 2012;96:622-31.

18 Chen G-C, Pang Z, Liu Q-F. Magnesium intake and risk of colorectal cancer: a metaanalysis of prospective studies. Eur J Clin Nutr 2012;66:1182-6.

19 HJ K, Youn CH, Kim HM, et al. Dietary magnesium intake and risk of cancer: a metaanalysis of epidemiologic studies. Nutr Cancer 2014;66:915-23.

20 Kennedy DA, Stern SJ, Moretti M, et al. Folate intake and the risk of colorectal cancer: a systematic review and meta-analysis. Cancer Epidemiol 2011;35:2-10.

21 Heine-Bröring RC, Winkels RM, Renkema JMS, et al. Dietary supplement use and colorectal cancer risk: a systematic review and meta-analyses of prospective cohort studies. Int. J. Cancer 2015;136:2388-401.

22 Liu Y, Yu Q, Zhu Z, et al. Vitamin and multiple-vitamin supplement intake and incidence of colorectal cancer: a meta-analysis of cohort studies. Med Oncol 2015;32:434.

23 Carroll C, Cooper K, Papaioannou D, et al. Meta-analysis: folic acid in the chemoprevention of colorectal adenomas and colorectal cancer. Aliment Pharmacol Ther 2010;31:708-18.

24 Qin T, Du M, Du H, et al. Folic acid supplements and colorectal cancer risk: metaanalysis of randomized controlled trials. Sci Rep 2015;5:12044.

25 Wien TN, Pike E, Wisleff T, et al. Cancer risk with folic acid supplements: a systematic review and meta-analysis. BMJ Open 2012;2:e000653.

26 Vieira AR, Abar L, Chan DSM, et al. Foods and beverages and colorectal cancer risk: a systematic review and meta-analysis of cohort studies, an update of the evidence of the WCRF-AICR continuous update project. Ann Oncol 2017;28:1788-802.

27 Aune D, Lau R, Chan DSM, et al. Dairy products and colorectal cancer risk: a systematic review and meta-analysis of cohort studies. Ann Oncol 2012;23:37-45.

28 Ralston RA, Truby H, Palermo CE, et al. Colorectal cancer and nonfermented milk, solid cheese, and fermented milk consumption: a systematic review and meta-analysis of prospective studies. Crit Rev Food Sci Nutr 2014;54:1167-79.

29 Aune D, Chan DSM, Lau R, et al. Dietary fibre, whole grains, and risk of colorectal cancer: systematic review and dose-response meta-analysis of prospective studies. BMJ 2011:343:d6617.

30 Trock B, Lanza E, Greenwald P. Dietary fiber, vegetables, and colon cancer: critical review and meta-analyses of the epidemiologic evidence. J Natl Cancer Inst 1990;82:650-61.

31 Haas P, Machado MJ, Anton AA, et al. Effectiveness of whole grain consumption in the prevention of colorectal cancer: meta-analysis of cohort studies. Int J Food Sci Nutr 2009:60:1-13

32 Gianfredi V, Salvatori T, Villarini M, et al. Is dietary fibre truly protective against colon cancer? A systematic review and meta-analysis. Int J Food Sci Nutr 2018;69:904-15.

33 Huxley RR, Ansary-Moghaddam A, Clifton P, et al. The impact of dietary and lifestyle risk factors on risk of colorectal cancer: a quantitative overview of the epidemiological evidence. Int J Cancer 2009:125:171-80.

34 Aune D, Lau R, Chan DSM, et al. Nonlinear reduction in risk for colorectal cancer by fruit and vegetable intake based on meta-analysis of prospective studies. Gastroenterology 2011;141:106-18.

35 Wu QJ, Yang Y, Vogtmann E, et al. Cruciferous vegetables intake and the risk of colorectal cancer: a meta-analysis of observational studies. Ann Oncol 2013;24:1079-87.

36 Tse G, Eslick GD. Cruciferous vegetables and risk of colorectal neoplasms: a systematic review and meta-analysis. Nutr Cancer 2014;66:128-39. 
37 Kashino I, Mizoue T, Tanaka K, et al. Vegetable consumption and colorectal cancer risk: an evaluation based on a systematic review and meta-analysis among the Japanese population. Jpn J Clin Oncol 2015;45:973-9.

38 Zhu B, Sun Y, Qi L, et al. Dietary legume consumption reduces risk of colorectal cancer: evidence from a meta-analysis of cohort studies. Sci Rep 2015;5:8797.

39 Woo HD, Park S, Oh K, et al. Diet and cancer risk in the Korean population: a metaanalysis. Asian Pac J Cancer Prev 2014;15:8509-19.

40 Tse G, Eslick GD. Soy and isoflavone consumption and risk of gastrointestinal cancer: a systematic review and meta-analysis. Eur J Nutr 2016;55:63-73.

41 Alkhenizan $A$, Hafez $\mathrm{K}$. The role of vitamin $\mathrm{E}$ in the prevention of cancer: a metaanalysis of randomized controlled trials. Ann Saudi Med 2007;27:409-14.

42 Bjelakovic G, Nikolova D, Simonetti RG, et al. Antioxidant supplements for preventing gastrointestinal cancers. Cochrane Database Syst Rev 2008;62:CD004183.

43 Arain MA, Abdul Qadeer A. Systematic review on "vitamin E and prevention of colorectal cancer". Pak J Pharm Sci 2010;23:125-30.

44 Papaioannou D, Cooper KL, Carroll C, et al. Antioxidants in the chemoprevention of colorectal cancer and colorectal adenomas in the general population: a systematic review and meta-analysis. Colorectal Dis 2011;13:1085-99.

45 Pais R, Dumitrascu DL. Do antioxidants prevent colorectal cancer? A meta-analysis. Rom J Intern Med 2013:51:152-63.

46 Druesne-Pecollo N, Latino-Martel P, Norat T, et al. Beta-carotene supplementation and cancer risk: a systematic review and metaanalysis of randomized controlled trials. Int. J. Cancer 2010;127:172-84.

47 Asano TK, McLeod RS. Nonsteroidal anti-inflammatory drugs and aspirin for the prevention of colorectal adenomas and cancer: a systematic review. Dis Colon Rectum 2004:47:665-73.

48 Wang X-J, Zeng X-T, Duan X-L, et al. Association between green tea and colorectal cancer risk: a meta-analysis of 13 case-control studies. Asian Pac J Cancer Prev 2012;13:3123-7.

49 Zhang Y-F, Xu Q, Lu J, et al. Tea consumption and the incidence of cancer: a systematic review and meta-analysis of prospective observational studies. Eur I Cancer Prev 2015;24:353-62.

50 Chen Y, Wu Y, Du M, et al. An inverse association between tea consumption and colorectal cancer risk. Oncotarget 2017;8:37367-76.

51 Sun C-L, Yuan J-M, Koh W-P, et al. Green tea, black tea and colorectal cancer risk: a meta-analysis of epidemiologic studies. Carcinogenesis 2006;27:1301-9.

$52 \mathrm{Hu}$ J-Y, Hu Y-W, Zhou J-J, et al. Consumption of garlic and risk of colorecta cancer: an updated meta-analysis of prospective studies. World I Gastroenterol 2014:20:15413-22.

53 Zhu B, Zou L, Qi L, et al. Allium vegetables and garlic supplements do not reduce risk of colorectal cancer, based on meta-analysis of prospective studies. Clin Gastroenterol Hepatol 2014;12:1991-2001.

54 Turati F, Guercio V, Pelucchi C, et al. Colorectal cancer and adenomatous polyps in relation to allium vegetables intake: a meta-analysis of observational studies. Mol Nutr Food Res 2014;58:1907-14.

55 Chung M, Lee J, Terasawa T, et al. Vitamin D with or without calcium supplementation for prevention of cancer and fractures: an updated meta-analysis for the U.S. preventive services task force. Ann Intern Med 2011;155:827-38.

$56 \mathrm{Ma}$ Y, Zhang P, Wang F, et al. Association between vitamin D and risk of colorectal cancer: a systematic review of prospective studies. J Clin Oncol 2011:29:3775-82.

57 Carroll C, Cooper K, Papaioannou D, et al. Supplemental calcium in the chemoprevention of colorectal cancer: a systematic review and meta-analysis. Clin Ther 2010;32:789-803.

58 Giovannucci E. Meta-analysis of coffee consumption and risk of colorectal cancer. Am J Epidemiol 1998:147:1043-52

59 Je Y, Liu W, Giovannucci E. Coffee consumption and risk of colorectal cancer: a systematic review and meta-analysis of prospective cohort studies. Int. J. Cancer 2009; 124:1662-8

60 Galeone C, Turati F, La Vecchia C, et al. Coffee consumption and risk of colorectal cancer: a meta-analysis of case-control studies. Cancer Causes Control 2010;21:1949-59.

$61 \mathrm{Li} \mathrm{G}, \mathrm{Ma}$ D, Zhang Y, et al. Coffee consumption and risk of colorectal cancer: a metaanalysis of observational studies. Public Health Nutr 2013;16:346-57.

62 Akter S, Kashino I, Mizoue T, et al. Coffee drinking and colorectal cancer risk: an evaluation based on a systematic review and meta-analysis among the Japanese population. Jpn J Clin Oncol 2016:46:781-7.

63 Gan Y, Wu J, Zhang S, et al. Association of coffee consumption with risk of colorectal cancer: a meta-analysis of prospective cohort studies. Oncotarget 2017:8:18699-711.

64 Geelen A, Schouten JM, Kamphuis C, et al. Fish consumption, n-3 fatty acids, and colorectal cancer: a meta-analysis of prospective cohort studies. Am J Epidemiol 2007;166:1116-25.

65 Wu S, Feng B, Li K, et al. Fish consumption and colorectal cancer risk in humans: a systematic review and meta-analysis. Am J Med 2012;125:551-9.

66 Shen X-J, Zhou J-D, Dong J-Y, et al. Dietary intake of $n-3$ fatty acids and colorectal cancer risk: a meta-analysis of data from 489000 individuals. Br J Nutr 2012;108:1550-6
67 Pham NM, Mizoue T, Tanaka K, et al. Fish consumption and colorectal cancer risk: an evaluation based on a systematic review of epidemiologic evidence among the Japanese population. Jpn J Clin Oncol 2013;43:935-41.

$68 \mathrm{XF}$ Y, Zou J, Dong J. Fish consumption and risk of gastrointestinal cancers: a metaanalysis of cohort studies. World J Gastroenterol 2014;20:15398-412.

69 Larsson SC, Orsini N, Wolk A. Vitamin B6 and risk of colorectal cancer: a meta-analysis of prospective studies. JAMA 2010;303:1077-83.

70 Weingarten MA, Zalmanovici A, Yaphe J, et al. Dietary calcium supplementation for preventing colorectal cancer and adenomatous polyps. Cochrane Database Syst Rev 2008:340:CD003548

71 Bristow SM, Bolland MJ, MacLennan GS, et al. Calcium supplements and cancer risk: a meta-analysis of randomised controlled trials. Br J Nutr 2013;110:1384-93.

72 Huncharek M, Muscat J, Kupelnick B. Colorectal cancer risk and dietary intake of calcium, vitamin $D$, and dairy products: a meta-analysis of 26,335 cases from 60 observational studies. Nutr Cancer 2009;61:47-69.

73 Keum N, Aune D, Greenwood DC, et al. Calcium intake and colorectal cancer risk: dose-response meta-analysis of prospective observational studies. Int. J. Cancer 2014;135:1940-8.

74 Dale KM, Coleman Cl, Henyan NN, et al. Statins and cancer risk: a meta-analysis. JAMA 2006;295:74-80.

75 Bardou M, Barkun A, Martel M. Effect of statin therapy on colorectal cancer. Gut 2010;59:1572-85.

76 Taylor ML, Wells BJ, Smolak MJ. Statins and cancer: a meta-analysis of case-control studies. Eur J Cancer Prev 2008;17:259-68.

77 Bonovas S, Filioussi K, Flordellis CS, et al. Statins and the risk of colorectal cancer: a meta-analysis of 18 studies involving more than 1.5 million patients. J Clin Oncol 2007:25:3462-8.

78 Browning DRL, Martin RM. Statins and risk of cancer: a systematic review and metaanalysis. Int. J. Cancer 2007:120:833-43.

79 Kuoppala J, Lamminpää A, Pukkala E. Statins and cancer: a systematic review and meta-analysis. Eur J Cancer 2008:44:2122-32.

80 Liu Y, Tang W, Wang J, et al. Association between statin use and colorectal cancer risk: a meta-analysis of 42 studies. Cancer Causes Control 2014;25:237-49.

81 Lytras T, Nikolopoulos G, Bonovas S. Statins and the risk of colorectal cancer: an updated systematic review and meta-analysis of 40 studies. World I Gastroenterol 2014:20:1858-70

82 Sandhu MS, White IR, McPherson K. Systematic review of the prospective cohort studies on meat consumption and colorectal cancer risk: a meta-analytical approach. Cancer Epidemiol Biomarkers Prev 2001;10:439-46.

83 Alexander DD, Cushing CA, Lowe KA, et al. Meta-analysis of animal fat or animal protein intake and colorectal cancer. Am J Clin Nutr 2009;89:1402-9.

84 Alexander DD, Weed DL, Cushing CA, et al. Meta-analysis of prospective studies of red meat consumption and colorectal cancer. Eur J Cancer Prev 2011;20:293-307.

85 Pham NM, Mizoue T, Tanaka K, et al. Meat consumption and colorectal cancer risk: an evaluation based on a systematic review of epidemiologic evidence among the Japanese population. Jpn J Clin Oncol 2014:44:641-50.

86 Longnecker MP, Orza MJ, Adams ME, et al. A meta-analysis of alcoholic beverage consumption in relation to risk of colorectal cancer. Cancer Causes Control 1990;1:59-68

87 Corrao G, Bagnardi V, Zambon A, et al. Exploring the dose-response relationship between alcohol consumption and the risk of several alcohol-related conditions: a meta-analysis. Addiction 1999;94:1551-73.

88 Bagnardi V, Blangiardo M, La Vecchia C, et al. A meta-analysis of alcohol drinking and cancer risk. Br J Cancer 2001;85:1700-5.

89 Moskal A, Norat T, Ferrari P, et al. Alcohol intake and colorectal cancer risk: a dose-response meta-analysis of published cohort studies. Int I Cancer 2007:120:664-71

90 Fedirko V, Tramacere I, Bagnardi V, et al. Alcohol drinking and colorectal cancer risk: an overall and dose-response meta-analysis of published studies. Ann Oncol 2011;22:1958-72.

91 Bagnardi V, Rota M, Botteri E, et al. Light alcohol drinking and cancer: a metaanalysis. Ann Oncol 2013;24:301-8.

92 Bagnardi V, Rota M, Botteri E, et al. Alcohol consumption and site-specific cancer risk: a comprehensive dose-response meta-analysis. $\mathrm{Br} J$ Cancer 2015;112:580-93

93 Wang $\mathrm{Y}$, Duan $\mathrm{H}$, Yang $\mathrm{H}$, et al. A pooled analysis of alcohol intake and colorectal cancer. Int J Clin Exp Med 2015;8:6878-89.

94 Zhang C, Zhong M. Consumption of beer and colorectal cancer incidence: a metaanalysis of observational studies. Cancer Causes Control 2015;26:549-60.

95 Jänne PA, Mayer RJ. Chemoprevention of colorectal cancer. N Engl J Med 2000;342:1960-8.

96 Smith DK, Demetriou T, Weber C. Aspirin for primary prevention: USPSTF recommendations for CVD and colorectal cancer. J Fam Pract 2019;68:146-51.

97 Moher D, Liberati A, Tetzlaff J, et al. Preferred reporting items for systematic reviews and meta-analyses: the PRISMA statement. PLoS Med 2009;6:e1000097. 